\title{
Regulación de la expresión del gen miostatina en epitelio mamario glucocorticoides.
}

\author{
Rosa Elvira Nuñez Anita ${ }^{a}$, Juan Carlos Santiago Jiménez ${ }^{\text {b }}$ y Marcos Cajero-Juárez ${ }^{c^{*}}$ \\ ${ }^{a}$ Facultad de Medicina Veterinaria y Zootecnia, Universidad Michoacana de San Nicolás de Hidalgo. Tarímbaro, Michoacán, México \\ ${ }^{b}$ Instituto de Investigaciones Químico Biológicas, Universidad Michoacana de San Nicolás de Hidalgo. Tarímbaro, Michoacán, México \\ ${ }^{c}$ Instituto de Investigaciones Agropecuarias y Forestales, Universidad Michoacana de San Nicolás de Hidalgo. Km. 9.5 Carretera \\ Morelia-Zinapécuaro. La Palma, cp. 58893. Tarímbaro, Michoacán. México.
}

*E-mail: cajeromarco@hotmail.com

Recibido 21 agosto 2013, Aceptado 01 octubre 2013

\begin{abstract}
Resumen
La proteína miostatina es el regulador negativo del crecimiento del músculo esquelético; miostatina se expresa además en la glándula mamaria, sin embargo, se conoce poco su papel en este órgano. Los glucocorticoides (GCs) son fármacos utilizados ampliamente en la medicina humana y veterinaria por su capacidad antiinflamatoria e inmunosupresora. Se conoce además que el gen mstn posee elementos "cis" de respuesta funcionales para los GCs. En este trabajo analizamos la participación de los GCs en la regulación la expresión del gen $m s t n$, en cultivo primario de células de epitelio mamario de bovino (EMB). Los resultados de PCR cuantitativa mostraron un comportamiento bifásico de la expresión del gen mstn. Además, la potencia de la expresión del gen mstn fue como sigue: a la concentración de $1 \mathrm{nM}$, Corticosterona > Prednisolona $>$ Hidrocortisona $>$ Dexametasona $>$ Fludrocortisona; a $10 \mathrm{nM}$, Prednisolona $>$ Hidrocortizona $>$ Corticosterona $>$ Dexametasona; a $100 \mathrm{nM}$, Hidrocortizona $>$ Corticosterona $>$ Dexametasona. Por el contrario, Betametasona favoreció la disminución de la expresión del gen mstn en todas las dosis empleadas. Este trabajo muestra que los GCs modulan la expresión en células EMB del gen $m s t n$ de forma diferencial.
\end{abstract}

Palabras clave: Glucocorticoides, miostatina, glándula mamaria, bovino, antiinflamatorio

\section{Introducción}

La masa muscular representa el equilibrio entre la replicación de células de músculo, la síntesis de proteínas, degradación de proteínas musculares, y la muerte celular $[1,2]$. La proteína miostatina (Mstn), anteriormente conocida como factor de diferenciación y crecimiento-8 (GDF-8), Mstn es un miembro de la superfamilia del factor de crecimiento beta, además es un regulador negativo del crecimiento del músculo esquelético y es responsable del correcto desarrollo de la masa muscular [3]. La hipertrofia del músculo esquelético se ha asociado con mutaciones que inactivan al gen mstn tanto en ratones como en bovinos $[1,4]$, generando el fenotipo doble músculo. Los efectos de Mstn sobre la proliferación de músculo esquelético se han estudiado directamente en las células musculares utilizando la proteína recombinante Mstn, los datos sugieren que esta proteína inhibe la masa muscular impidiendo la replicación de las células del músculo y la regulación de la síntesis de proteínas [5].

Manickam [6] demostró que el gen $m$ stn se expresa en el tejido adiposo, cardiaco, óseo, y la glándula mamaria. Sin embargo, se sabe poco acerca de la función fisiológica del gen mstn en la glándula mamaria. Algunos autores han propuesto que el gen mstn puede actuar como un factor autócrino, debido a su capacidad para inducir la actividad transcripcional en las células mamarias [7]. Otros autores han propuesto que la expresión del gen mstn en la glándula mamaria se asocia principalmente con las células epiteliales y muestra una correlación inversa con el estado diferenciado de la glándula. Los más altos niveles del ARN mensajero (ARNm) de mstn se correlacionan con períodos de crecimiento ductal máximo, mientras que los más bajos se han detectado durante la gestación. Además, se han detectado niveles muy bajos de ARNm en el inicio de la lactación en el epitelio diferenciado [8].

La glándula mamaria proporciona un excelente sistema para investigar la regulación hormonal de la expresión génica, así como la diferenciación celular [9]. En general, células de la glándula mamaria representan un buen modelo para investigar la regulación de la expresión génica inducida por Glucocorticoides (GCs) sobre el gen mstn, debido a los altos niveles de expresión de ARNm en este tejido.

El objetivo de este trabajo fue analizar si distintos GCs son capaces de regular la expresión del gen mstn, en este trabajo utilizamos los siguientes compuestos: Betametasona GC (Beta), Corticosterona (Cort), Dexametasona (Dexa), Fludocortisone (Flud), Hidrocortisona (Hydro), Prednisolona (Pred) y Triamicinolone (Triam). Nuestros resultados mostraron expresión diferencial del gen mstn después del 
tratamiento con diferentes GCs, además de mostrar una curva de expresión que corresponde a un comportamiento bifásico (El mayor aumento se observó en la dosis más baja).

\section{Parte experimental}

2.1. Los GCs y los oligonucleótidos se obtuvieron de Sigma-Aldrich (St. Louis, MO). El medio de cultivo usado fue DMEM/F-12K, además de suero bovino de ternera y penicilina-estreptomicina obtenidos de Invitrogen (Carlsbad, CA). Todos los demás productos químico utilizados fueron de la más alta calidad y pureza disponible comercialmente, provistos por Sigma-Aldrich.

\subsection{Células epiteliales mamarias bovinas (EMB).}

Las células EMB fueron aisladas de muestras de tejido de biopsia obtenidas a partir de una glándula mamaria bovina en período de lactancia. Brevemente, el tejido se lavó con solución salina tamponada de fosfatos (PBS) y se sumergió en $70 \%$ de etanol durante $20 \mathrm{~min}$. El tejido lobular se diseccionó y se lavó tres veces con PBS. Luego, las células se disgregaron mediante el uso de una solución de digestión (300 U / ml de colagenasa tipo I; $0,05 \%$ de colagenasa tipo II; $100 \mathrm{U} / \mathrm{ml} \mathrm{de}$ DNasa; $1 \%$ de penicilina-estreptomicina) durante 90 min a $37^{\circ} \mathrm{C}$. La suspensión celular se centrifugó, y el sedimento se resuspendió en medio de cultivo DMEM/F-12K suplementado con $10 \%$ de suero bovino de ternera y $50 \mathrm{U} / \mathrm{ml}$ de penicilina-estreptomicina, 10 $\mathrm{mg} / \mathrm{ml}$ de insulina, y $1 \mathrm{pM}$ de Dexametasona [10]. El medio libre de Dexa se utilizó para los experimentos. Para la propagación, las células EMB se cultivaron en placas de petri de $100 \mathrm{~mm}$ (Corning Costar Corp.,
Cambridge, MA), y se mantuvo a $37^{\circ} \mathrm{C}$ en una atmósfera humidificada que contiene $5 \%$ de $\mathrm{CO}_{2}$. El medio se cambió cada dos días hasta lograr la confluencia.

Para determinar la viabilidad temporal de las células EMB, se realizó un conteo directo utilizando un hemocitómetro y en cada paso las células EMB se sembraron en el mismo número inicial en a una nueva placa. Por otro lado, para garantizar la naturaleza de los cultivos celulares, se realizó RT-PCR para el gen de prolactina y el gen de K-caseína.

\subsection{PCR en tiempo real (RT-PCR)}

Las células EMB se cultivaron a una densidad de 1,5 x $10^{5}$ células / placa en medio basal durante $24 \mathrm{~h}$, se cambió el medio, y las células fueron tratadas con el vehículo etanol (control), 1, 10, o $100 \mathrm{nM}$ de los diversos GCs durante $96 \mathrm{~h}$. Después de la incubación, el ARN total se extrajo usando el kit comercial para aislamiento de ARN (Roche Applied Science, Indianápolis, IN) de acuerdo a las instrucciones del fabricante. Se utilizaron dos microgramos de ARN total el cual fue retro-transcrito utilizando el sistema Superscript II (Invitrogen, Carlsbad, CA). El RT-PCR se realizó usando el sistema de detector de 3000 RotoGen Sequence (Corbett Research, Mortlake, NSW, Australia), utilizando SYBR Green como un marcador para la amplificación de ADN. La reacción se realizó con $1 \mu 1$ de cDNA y el kit comercial de Supermix-UDG para PCR cuantitativa (Invitrogen), utilizando 30 ciclos de programa de amplificación de tres pasos $\left(94{ }^{\circ} \mathrm{C}\right.$ durante $30 \mathrm{~s}, 52-58^{\circ} \mathrm{C}$ durante $90 \mathrm{~s}, 72{ }^{\circ} \mathrm{C}$ durante $90 \mathrm{~s}$ ) con los oligoprimers específicos de gen, mismos que se presentan en la Tabla 1.

Tabla 1. Secuencia de oligonucleotidos usados para el análisis de los genes $m s t n$, prolactina, $\mathrm{K}$-caseina, y $\beta$-actina, con su respectivo tamaño predicho del amplicon.

\begin{tabular}{clcc}
\hline Gen & \multicolumn{1}{c}{$\begin{array}{c}\text { Secuencia de } \\
\text { oligonucleotidos }\left(5^{\prime}-3^{\prime}\right)\end{array}$} & $\begin{array}{c}\text { Temperatura de } \\
\text { alineación }\left({ }^{\circ} \mathrm{C}\right)\end{array}$ & Tamaño (bp) \\
\hline \multirow{2}{*}{ mstn } & $\begin{array}{c}\text { s-CCCAACTGTGGATATATCTG } \\
\text { a-TACCAGTGCCTGGGTTCATG }\end{array}$ & 55 & \multirow{2}{*}{644} \\
\hline \multirow{2}{*}{ Prolactina } & $\begin{array}{l}\text { s-TGTGTTTCTTGAAATCATCACC } \\
\text { a-AAGTGTCAATCTTGCTTGAATC }\end{array}$ & 57 & \multirow{2}{*}{351} \\
\hline \multirow{2}{*}{ K-Caseína } & $\begin{array}{l}\text { s-AGCAAGAGCTGACGGTCACAA } \\
\text { a-TGGCAGGCACAGTATTTGACA }\end{array}$ & 58 & 215 \\
\hline \multirow{2}{*}{$\beta$-Actina } & $\begin{array}{l}\text { s-AGCAGGAGATGGCCAC } \\
\text { a-GGCGTAGAGGTCCTTG }\end{array}$ & 52 & \multirow{2}{*}{5} \\
\hline
\end{tabular}

La reacción de PCR generó sólo las amplificaciones de ADN específicas esperadas, esto se demostró en cada caso por el perfil de temperatura de fusión (curva de disociación) y por electroforesis de $5 \mu \mathrm{l}$ del producto de 
PCR usando un gel de agarosa al 1,5\% teñido con bromuro de etidio en tampón Tris-borato-EDTA. No se observaron productos de la PCR en ausencia de ADN (control negativo). La expresión génica se calculó utilizando el ciclo umbral (delta CT), dicho método fue normalizado para el contenido de $\beta$-actina, que corresponde a un gen de expresión constitutivo no regulado. Todas las mediciones se realizaron por triplicado.

\subsection{Análisis estadístico}

Los datos informados son los valores medios de al menos tres experimentos independientes, cada uno implico tratamientos por triplicado, y se expresan como medias \pm errores estándar de las medias. La significación estadística entre los grupos se determinó mediante un análisis de varianza seguido por la prueba de la $t$ de Student para datos independientes, usando el software GraphPad Prism 5.0 (La Jolla, CA). Las diferencias en los medios con los valores de $p$ de $<0,05$ se consideraron estadísticamente significativos.

\section{Resultados y discusión}

\subsection{Caracterización de las células EMB}

Las células EMB se mantuvieron en forma continua en cultivos subconfluentes, su tiempo de replicación celular fue de $24 \mathrm{~h}$, de acuerdo con el conteo de células realizado cada $24 \mathrm{~h}$ utilizando un hemocitómetro. La senescencia de los cultivos primarios se caracteriza por la falta de división celular, el aumento de volumen de la célula, y la muerte celular de acuerdo con Jha [11]. Alrededor del pasaje 8, fue evidente una reducción de la proliferación celular (Figura 1A) y un aumento en el volumen celular (datos no presentados), lo que indica la senescencia celular. Por lo tanto, los experimentos se realizaron cuando las células se encontraban en los pasajes celulares 2 a 7 . En pasajes iniciales, las células EMB mostraron una organización que asemeja a la estructura del alveolo lactogénico, misma que representa una característica de las células mamarias diferenciadas (Figura 1B). Para la caracterización molecular se determinó expresión de los genes: prolactina, K-caseína, y mstn. La línea celular de EMB mostró expresión de genes específicos de tejido, lo que confirma su fenotipo de glándula mamaria (Figura 1C).

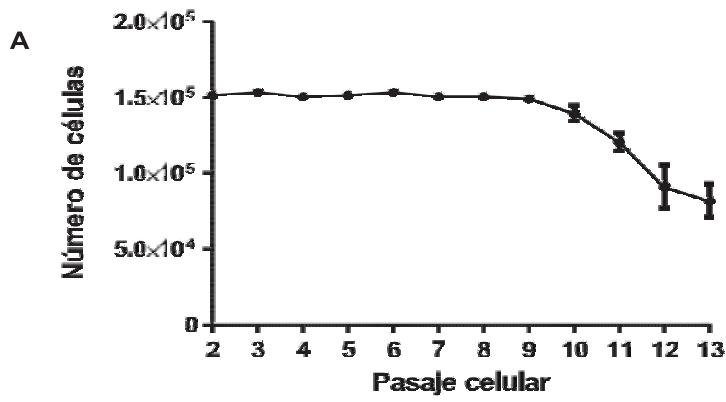

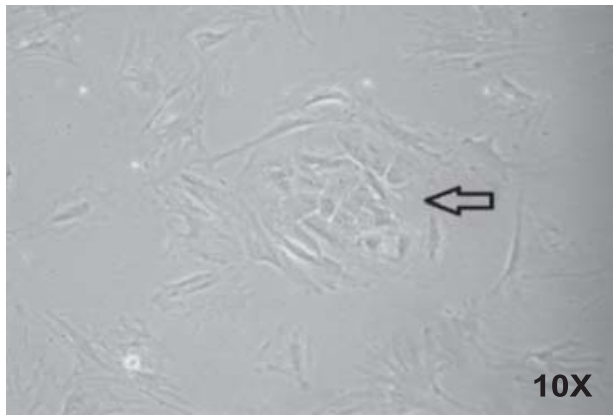

C

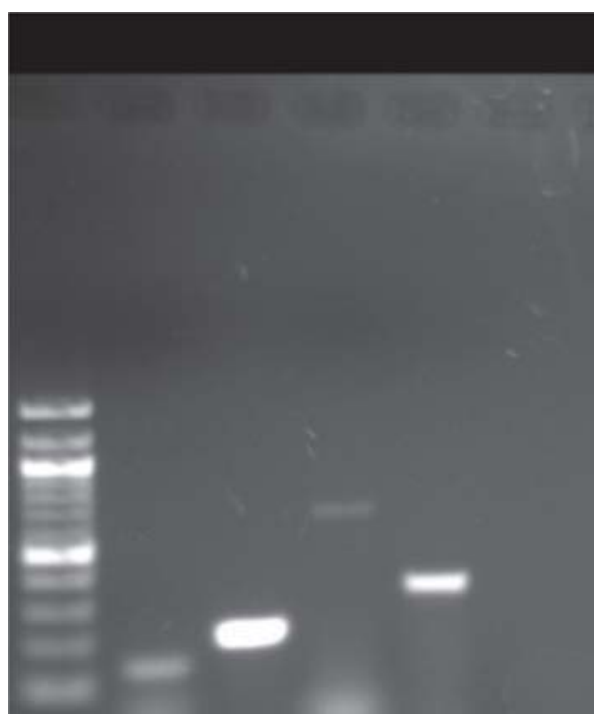

Figura 1. Caracterización de las células EMB. A) Vida útil in vitro de las células EMB. Las células se sembraron a una densidad de $1,5 \times 10^{5}$ por plato de $60 \mathrm{~mm}$, y el número de células por placa se registró en cada pasaje (realizado cada 48 h). B) Morfología de las células EMB (pasaje 4). La flecha muestra la organización de células similar a la luz alveolar, una característica de las células mamarias. C) Productos de RTPCR utilizando ARN total de las células EMB. Carril M, Marcador de peso molecular 100pb (New England Biolabs); carriles $1,2,3,4$, y 5 corresponden a $m s t n$, $\square$-actina, prolactina, k-caseína, y el control negativo, respectivamente.

\subsection{Regulación de la expresión del ARNm del gen mstn por GCs}

Las células EMB fueron tratadas con 0, 1, 10, o 100 nM de cada uno de los GC, los niveles de expresión de ARNm para mstn se determinaron mediante PCR cuantitativa (oligonucleótidos de la Tabla 1) y se compararon con los niveles presentes en las células de control. Los datos muestran una curva bifásica para la expresión de ARNm de mstn en respuesta a la mayoría de los GCs evaluados: a $1 \mathrm{nM}$, la expresión de ARNm del gen $m s t n$ se estimuló de la siguiente manera, Cort> Pred $>$ Hydro $>$ Dexa $>$ Flud, mientras que a $10 \mathrm{nM}$ sólo algunos de los GC (Pred $>$ Hydro $>$ Cort $>$ Dexa) indujeron un aumento, a $100 \mathrm{~nm}$, la GC Hydro> Cort> 
Dexa indujeron aumento (Figura 2). Estos resultados contrastan con los efectos observados en las células tratadas con Beta, que indujeron una disminución de la expresión de ARNm de mstn en todas las dosis, mientras que el tratamiento con Triam sólo provocó una disminución de la expresión de ARNm de mstn a 100 nM (Figura 3).

A

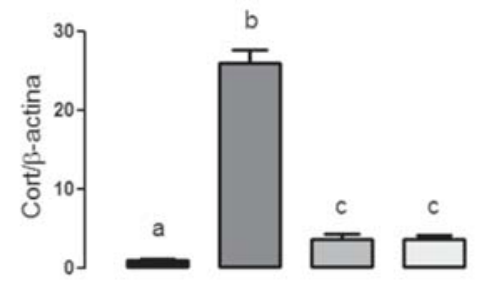

B
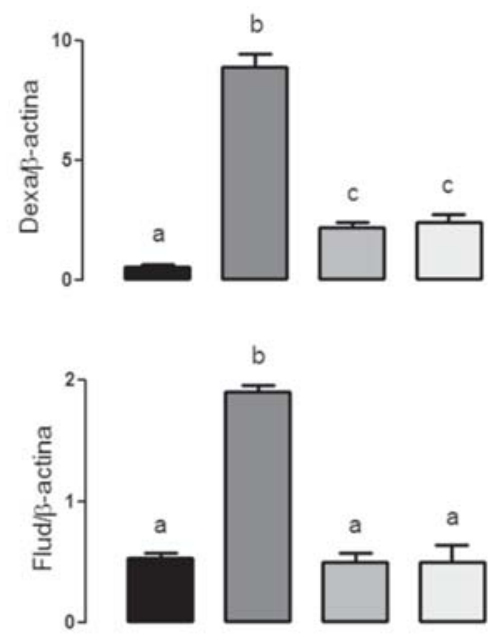

D

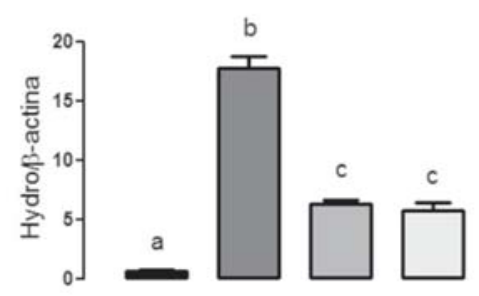

E

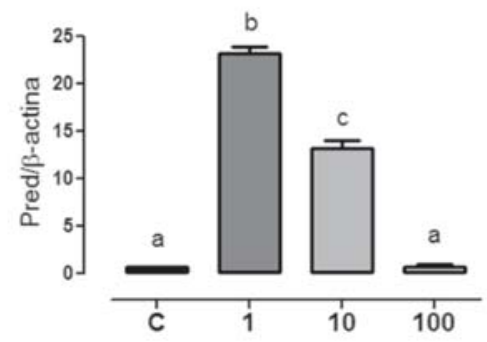

Figura 2. Los aumentos en la expresión mstn inducidos por Cort, Dexa, Flud, Hydro y Pred. Las células EMB fueron tratados con vehículo de control (C) ó 1, 10, ó $100 \mathrm{nM}$ de cada uno de los GCs durante $96 \mathrm{~h}$. El ARNm para mstn se cuantificó utilizando el método de RT-PCR. El gen de $\beta$-actina sirvió como un control interno y se utilizó para normalizar las diferencias de ARN usadas en cada caso. Las diferentes letras minúsculas por encima de las barras indican diferencias significativas $(\mathrm{p}<0,05)$.
A

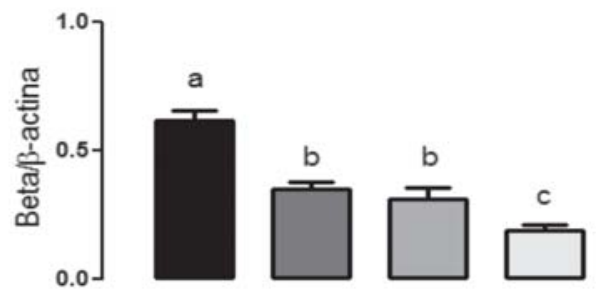

B

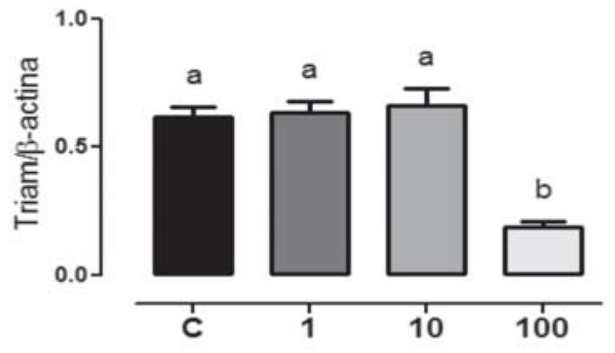

Figura 3. Beta y Triam favorecen la disminución de la expresión de mstn. Las células EMB fueron tratadas con vehículo de control (C) ó 1, 10, ó $100 \mathrm{nM}$ de cada uno de los GC después de $96 \mathrm{~h}$ de tratamiento. El ARNm para mstn se cuantificó mediante RT-PCR. EL gen de $\beta$-actina sirvió como un control interno y se utilizó para normalizar las diferencias en el ARN de carga usadas en cada muestra. Las diferentes letras minúsculas por encima de las barras indican diferencias significativas $(\mathrm{p}<0,05)$.

Los datos en este estudio mostraron que las células EMB expresan marcadores moleculares específicos de la diferenciación de células epiteliales mamarias. Mostramos además que una baja concentración de los GCs $(1 \mathrm{nM})$ induce una fuerte expresión del gen $m s t n$, en comparación con las dosis de $10 \mathrm{nM}$ y $100 \mathrm{nM}$. Por el contrario, los tratamientos con Beta mostraron disminución de la expresión del gen mstn en todas las dosis empleadas, mientras que Triam sólo provoco la disminución de la expresión del gen mstn a $100 \mathrm{nM}$.

Se ha descrito en la literatura que Mstn se traduce como una proteína precursora que se procesa mediante proteolisis para generar un propéptido $\mathrm{N}$-terminal y un dímero C-terminal, que es la forma biológicamente activa. Tras el procesamiento proteolítico, el propéptido permanece unido a la dímero C-terminal lo que mantiene un complejo latente inactivo, y esto representa una de las principales formas de Mstn que circulan en la sangre $[12,13]$. Además, otras proteínas de unión son capaces de regular la actividad mstn in vitro, incluyendo folistatina, el producto del gen relacionado con folistatina (FRGP), y factor de crecimiento y diferenciación asociada a la proteína de suero-1 (GASP1) y además se conoce que Mstn puede actuar a través de receptores de ActRIIB [13]. Algunos estudios han mostrado que los mioblastos cultivados expresan una isoforma ActRIIB diferente que la línea celular de 
adenocarcinoma de mama humano (MCF-7). Sin embargo, Mstn puede transducir señales a través de ambas isoformas, por lo que es poco probable que esta diferencia sea considerada para la especificidad en la señalización de Mstn.

Por otro lado, se sabe que los GCs son compuestos anti-inflamatorios e inmunosupresores potentes que se utilizan ampliamente en la medicina humana y veterinaria. Todos los miembros de la familia de los GCs muestran similitudes estructurales, con ligeras diferencias en sus grupos funcionales. Los GCs tienen un efecto regulador directo en el promotor del gen $\mathrm{mstn}$, ya que se ha descrito que contiene elementos " cis $^{20}$ de respuesta a GCs funcionales [14]. De hecho, Dexa puede regular tanto el ARNm como a la proteína Mstn en las células del músculo esquelético in vitro de una manera dependiente de la dosis, lo que indica que Dexa induce un aumento en la expresión del ARNm de Mstn por inducción directa de la transcripción [14]. Otros autores han propuesto que la administración de dosis elevadas de GCs induce atrofia muscular, principalmente debido a la estimulación de la proteólisis de las células del músculo [15].

Ma y colaboradores [14] analizaron el efecto sobre la expresión de mstn utilizando Dexa en células del músculo esquelético. Ellos observaron un aumento en las concentraciones del ARNm y de la proteína Mstn. Se ha sugerido que Dexa podría tener efectos reguladores postraduccionales, es decir, a nivel de la proteína Mstn, dichos resultados tendrán que ser analizados más a fondo.

Los GCs son ampliamente utilizados para el tratamiento de varios trastornos inflamatorios, se conoce bien su capacidad para inducir la atrofia muscular en seres humanos y animales. Algunos estudios in vitro e in vivo han sugerido que los efectos de los GCs en el músculo están mediadas a través de la inhibición de la síntesis de proteínas y un aumento en la degradación de proteínas. Los mecanismos moleculares precisos por los que los GCs inducen los efectos catabólicos se han investigado en las células musculares. Se ha propuesto que los GCs también ejercen una acción anti-anabólica por detener ó frenar de la síntesis de proteínas del músculo. Estos cambios en la expresión o represión de proteínas pueden resultar de cambios en la producción de dos factores de crecimiento que controlan masa muscular, a saber, el factor de crecimiento similar a la insulina I (IGF-I) y mstn, que tienen efecto anabólico y catabólico en músculo esquelético respectivamente. Se ha demostrado que tanto la disminución de la producción de IGF-I, así como aumento de la producción de Mstn contribuyen a la atrofia muscular causada por GCs. A nivel molecular, el IGF-I antagoniza la acción catabólica de los GCs mediante la inhibición, a través de la vía de 3-
kinase/Akt fosfatidilinositol, la actividad del factor de transcripción FOXO, un interruptor principal para la estimulación de la expresión de varios genes implicados en la atrofia muscular (nombrados algunas veces como atrogenes) [16].

Con respecto a patologías de la glándula mamaria, recientemente se propuso que GCs juegan un papel muy complejo en la epidemiología, la biología y el tratamiento del cáncer de mama [17]. Los GCs juegan un papel esencial en el desarrollo embrionario y la homeostasis del tejido y poseen propiedades antiinflamatorios e inmunosupresores importantes. Los GCs son un componente importante de los regímenes de tratamiento en enfermedades malignas hematológicas, debido a sus propiedades pro-apoptóticas, y que también se utilizan como co-tratamiento en varios otros tipos de cáncer y en los regímenes de quimioterapia, incluyendo algunos para el tratamiento del cáncer de mama. En el cáncer de mama, sin embargo, los GC pueden tener efectos diversos y pueden inhibir la quimiosensibilidad.

\section{Conclusiones}

Se obtuvieron cultivos de células EMB alveolar de una glándula mamaria lactante. Las células EMB representan un buen modelo para investigar la expresión génica y la proliferación después del tratamiento hormonal. Nuestros resultados mostraron un comportamiento bifásico en la expresión de gen mstn en respuesta a la mayoría de los GCs utilizados. Nuestros resultados sugieren que las diferencias en las estructuras moleculares de los diferentes GCs resultado en efectos diferenciales sobre las células EMB.

\section{Conflicto de intereses.}

Los autores declaran no tener conflictos de intereses.

\section{Agradecimientos}

Nuñez-Anita agradece al programa de RetenciónRepatriación-CONACYT (173382). Santiago-Jiménez fue patrocinado por una beca de CONACYT (188629). Este trabajo fue parcialmente apoyado por becas CICUMSNH 2012 y SAGARPA-CONACYT.

\section{Referencias}

1. Grobet, L.; Pirottin, D.; Farnir, F.; et al. Genesis 2003; 35, 227-238.

2. Reisz-Porszasz, S.; Bhasin, S.; Artaza, J.N.; et al. Am J Phys Endocrinol Met 2003; 285, E876- E888.

3. McPherron, A.C.; Lee, S.J.; et al. PNAS USA 1997; 94, 12457-12461.

4. Mcpherron, A.C.; Lawler, A.M.; Lee, S.J.; et al. Nat 1997; 387, 83-90.

5. Taylor, W.E.; Bhasin, S.; et al. Artaza, J. Am J Phys Endocrinol Met 2001; 280, E221_E228. 
6. Manickam, R.; Pena, R.N.; Whitelaw, C.B.A.; et al. Mol Rep Dev 2008; 75, $1783-1788$

7. Ríos, R.; Fernández-Nocelos, S.; Carneiro, I.; et al. Endocrinol 2004; 145, 2795 -2803.

8. Su, Z.; Dong, X.; Zhang, B.; et al. Sci China C, Life Sci 2006; 49, 26-36.

9. Levine, J.F.; Stockdale, F.E.; et al. J Cell Biol 1985; 100, 1415-1422.

10. Machuca, M.; Mendoza-Milla, C.; Córdova, E.; et al. BMC Cell Biology 2006; 7, 9.

11. Jha, K.K.; Banga, S.; Palejwala, V.; et al. Exp Cell Res 1998; 245, 1-7.

12. Hill, J.J.; Davies, M.V.; Pearson, A.A.; et al. J Biol Chemi 2002; $277,40735-40741$.

13. Lee, S.J.; McPherron, A.C.; et al. PNAS USA 2001; 98, 9306-9311.

14. Ma, K.; Mallidis, C.; Artaza, J.; et al. Am J Phys Endocrinol Met 2001; 281, E1128-E1136.

15. Kanda, F.; Takatani, K.; Okuda, S.; et al. Muscle Nerve 1999; 22, 213-217.

16. Schakman, O.; Gilson, H.; Thissen, J.; et al. J Endocrinol 2008; 197, 1-10.

17. Vaidya, J.S.; Baldassarre, G.; Thorat, M.A.; et al. Curr Pharm Design, 2010; 16, 3593 - 3600. 